\title{
ANALYSIS OF THE INFLUENCE OF LASER IRRADIATION ON THE ACCUMULATION OF BIOMASS AND POLYSACCHARIDES PLEUROTUS OSTREATUS (JACQ.) P. KUMM
}

\author{
K. Reshetnyk
}

The aim of the study was to investigate the effect of laser irradiation of mycelium on the amount of biomass and synthesis of $P$. ostreatus polysaccharides.

Materials and methods. For the study, 6 strains of P. ostreatus from the Collection of cultures of basidiomycetes of the Department of Botany and Ecology of Vasyl Stus DonNU were used. A device consisting of LED lasers was used for laser irradiation of vegetative mycelium: BRP - 3010-5, with red spectrum radiation with a wavelength of $635 \mathrm{~nm}$; $B B P-3010-5$ with blue spectrum radiation with a wavelength of $405 \mathrm{~nm}$ and BGP - 3010-5 with green spectrum radiation with a wavelength of $532 \mathrm{~nm}$. The level of biomass accumulation was determined by weight. The polysaccharide content was determined by the phenol-sulfur method.

Results. The most effective was green light irradiation with a wavelength of $532 \mathrm{~nm}$. For strain P-192 - the amount of biomass increased by $71.4 \%$. For strains $P-191$ and P-155 biomass increased by $60 \%$ and $53.5 \%$. For strains $P$-108, $P-154$ and P-6v, the amount of biomass increased from 33.3 to $50 \%$. For strain P-192, the amount of mycelial endopolysaccharides increased by $42.0 \%$. For strains $P-191$ and $P-6 v$, the amount of endopolysaccharides increased by $39.3 \%$ and $38.7 \%$. For strains $P-108, P-155$ and $P-154$ the amount of mycelium endopolysaccharides increased from $30.7 \%$ to 35.8 . For strain P-192 the content of exopolysaccharides increased by $30.5 \%$. For strains P-154 and P-191, the amount of exopolysaccharides increased by $28.1 \%$ and $27.8 \%$. For strains P-108, P-155 and P-6v the content of exopolysaccharides increased from $24.6 \%$ to $25.8 \%$.

Conclusions. The most effective mode of photoactivation of P. ostreatus mycelium for obtaining target products was determined. In particular, the best response was observed in response to green light with a wavelength of $532 \mathrm{~nm}$ for strain P-192 - the amount of biomass increased by $71.4 \%$, the amount of mycelium endopolysaccharides increased by $42.0 \%$, and the content of exopolysaccharides increased by $30.5 \%$

Keywords: Pleurotus ostreatus, laser irradiation, surface cultivation, photoactivation, vegetative mycelium, polysaccharides

\section{Introduction}

Pleurotus ostreatus belongs to the fungi that cause white rot of wood and has a well-developed enzymatic apparatus that is able to absorb a variety of carbon-containing substrates $[1,2]$. P. ostreatus contains a significant amount of protein, polysaccharides and other biologically active substances (BAS), which have antimicrobial, antiviral, antitumor, antioxidant, hyperglycemic, anti-inflammatory, hepatoprotective, hypocholesterolemic, immunomodulatory properties [3]. The prospects of its study are also due to the fact that in terms of production in Ukraine it ranks second place, and industrial cultivation of this fungus is $16.3 \%$ of total world production [4]. P. ostreatus attracts the attention of scientists due to its accessibility and ease of use. This allows the introduction of new modern methods of intensification of growth and biochemical parameters of this fungus. In particular, this method is laser irradiation of the mycelium, which can significantly improve the growth and development of fungi. It should be noted that the use of helium-neon and argon lasers, which have large dimensions and significant energy consumption, complicates the technology of stimulating the growth and development of fungi [5]. In our opin- ion, it is much more effective to use LED lasers to intensify the metabolic processes of macromycetes [6].

\section{Literary review}

From the literature it is known that the cultivation of mycelium of $P$. ostreatus is more economical and takes less time compared to growing fruit bodies. Scientists pay special attention to obtaining biomass [4] and polysaccharides of $P$. ostreatus [7, 8]. The influence of substrates from extracts of waste sunflower husk, oat seed meal, milk thistle, flax, pumpkin, mustard, rose hips, wheat germ, amaranth seed meal, rapeseed meal, sunflower, ryegrass, walnut, yam, sweet and ordinary potato, cattail rhizome, plantain on biomass characteristics and oyster fungus metabolites [7, 9]. The stimulating effect of yam extract on the accumulation of $P$. ostreatus biomass and exopolysaccharides has been proved [7, 9]. It is known that the use of a mixture of winemaking waste and wheat bran gave a high yield of $P$. ostreatus biomass [10]. Irradiation of sowing mycelium of $G$. $l u$ cidum and $L$. edodes with both coherent and incoherent light of low intensity, where as a source of coherent visible light used modifications of gas lasers: helium-neon LGN-215 with radiation at a wavelength of $632.8 \mathrm{~nm}$ 
(red light ) and argon ion laser (modified model LGN$106 \mathrm{M} 1$ ) - radiation with a wavelength of 514.5 (green light) and $488.0 \mathrm{~nm}$ (blue light) caused an increase in polysaccharide synthesis and the amount of biomass [11]. In previous studies, we found that laser irradiation of vegetative mycelium of $P$. ostreatus with light of different spectral composition activates mycelial growth, so we hypothesized that the use of photoactivated mycelium will increase the synthesis of biologically active substances and the amount of biomass [6].

\section{The purpose and objectives of the study}

The aim of the study was to study the effect of laser irradiation of mycelium on the amount of biomass and synthesis of $P$. ostreatus polysaccharides. solved:

To solve this purpose, the following tasks were

1. To establish the effect of laser irradiation with light of different spectral composition on the amount of biomass of the fungus $P$. ostreatus.

2. To investigate the effect of laser irradiation on the synthesis of polysaccharides of the fungus $P$. ostreatus.

3. Determine the most effective mode of photoactivation of $P$. ostreatus mycelium to obtain target products.

\section{Materials and methods of research}

The research was conducted at the Department of Botany and Ecology of Vasyl Stus Donetsk National University (Vasyl Stus DonNU). Six strains of the fungus $P$. ostreatus from the Collection of cultures of basidiomycetes of the Department of Botany and Ecology of Vasyl Stus DonNU, which are part of the Basidiomycota department, were used for the study. To obtain the inocu- lum of mycelium strains P-191, P-192, P-6v, P-154, P-155, P-108 of the fungus $P$. ostreatus was cultured on agar glucose-peptone medium (GPA), g / 1: glucose 10.0; peptone - 3.0; $\mathrm{KH}_{2} \mathrm{PO}_{4}-0.6 ; \mathrm{K}_{2} \mathrm{HPO}_{4}-0.4$; $\mathrm{MgSO}_{4} 7 \cdot \mathrm{H}_{2} \mathrm{O}-0.5 ; \mathrm{CaCl}_{2}-0.05 ; \mathrm{ZnSO}_{4} \cdot 7 \mathrm{H}_{2} \mathrm{O}-0.001$, distilled water - up to $1 \mathrm{dm}^{3}$; agar-agar - 15 in Petri dishes at a temperature of $26 \pm 1{ }^{\circ} \mathrm{C}$. In the study of the effect of laser irradiation of the mycelium in the surface culture used glucose-peptone liquid nutrient medium (GPM), g/l: glucose - 10.0; peptone - 3.0; $\mathrm{KH}_{2} \mathrm{PO}_{4}-0.6$; $\mathrm{K}_{2} \mathrm{HPO}_{4}-0.4 ; \mathrm{MgSO}_{4} 7 \cdot \mathrm{H}_{2} \mathrm{O}-0.5 ; \mathrm{CaCl}_{2}-0.05 ;$ $\mathrm{ZnSO}_{4} \cdot 7 \mathrm{H}_{2} \mathrm{O}-0.001$, distilled water - up to $1 \mathrm{dm}^{3}$. The mycelium was cultured for 12 days at $26 \pm 1{ }^{\circ} \mathrm{C}$ in a thermostat in $250 \mathrm{ml}$ Erlenmeyer flasks containing $50 \mathrm{ml}$ of GPM nutrient medium. Inoculation was performed with disks of mycelium of cultures grown on GPA. Five disks with a diameter of $5 \mathrm{~mm}$ were cut with a sterile steel tube at a distance of $8-10 \mathrm{~mm}$ from the edge of the active growth of the colony.

For laser irradiation of the vegetative mycelium, a device consisting of an octagonal mirror prism that perceives the beam of LED lasers was used: BRP - 3010-5, with red spectrum radiation with a wavelength of $635 \mathrm{~nm}$; BBP - 3010-5 with blue spectrum radiation with a wavelength of $405 \mathrm{~nm}$ and BGP - 3010-5 with green spectrum radiation with a wavelength of $532 \mathrm{~nm}$ (laser manufacturer BOB LASER Co., China) and reflects it on the conveyor belt on which the cup is placed Petri dish with mycelium. The power of each laser is $100 \mathrm{~mW}$. The device has two electric motors that are responsible for the movement of the mirror prism and the conveyor belt. The device is controlled by a control panel equipped with buttons to adjust the exposure time and select the desired laser with the appropriate wavelength of light (Fig. 1).

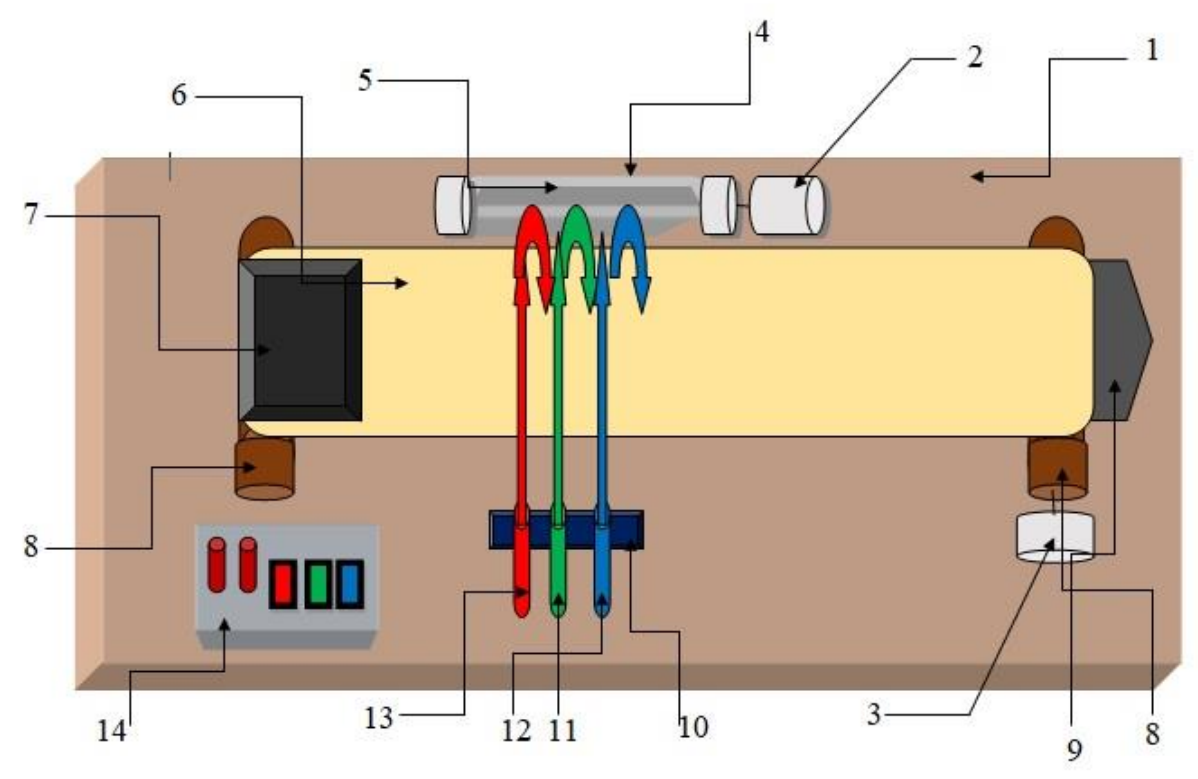

Fig. 1. Device for irradiating mycelium with monochromatic light using LED lasers: 1 - platform for mounting the device, 2 - electric motor 1, 3 - electric motor 2, 4 - protective cover for a mirror prism, 5 - mirror prism, 6 - conveyor belt, 7 - hopper for irradiated objects, 8 - the roller that moves the conveyor belt, 9 - platform for irradiated objects, 10 - tripod for mounting LED lasers, 11 - LED laser BGP-3010-5 with green spectrum radiation with a wavelength of $532 \mathrm{~nm}, 12$ - LED laser BBP-3010-5 with blue spectrum radiation with a wavelength of $405 \mathrm{~nm}, 13$ - LED laser BRP$3010-5$, with red spectrum radiation with a wavelength of $635 \mathrm{~nm}, 14$ - control panel 
The mycelium was irradiated as follows: a Petri dish with mycelium moves on a conveyor belt under a beam of light with a set wavelength: 635, 405 and $532 \mathrm{~nm}$, obtaining the required irradiation energy $\left(51.1 \mathrm{~mJ} / \mathrm{cm}^{2}\right)$. Irradiation of the mycelium lasted $10 \mathrm{~s}$. Then, using a sterile steel tube, $5 \mathrm{~mm}$ diameter mycelial discs were excised from the mycelial colony and inoculated onto a liquid nutrient medium (GPM) of appropriate composition.

An irradiated culture was used to inoculate the control Petri dishes. Irradiation of the mycelium was performed in several variants (Table 1).

Scheme of irradiation of the mycelium of the Pleurotus ostreatus fungus

\begin{tabular}{|c|c|c|c|c|}
\hline \multirow[b]{2}{*}{ Irradiation option } & \multicolumn{3}{|c|}{ Duration of irradiation, $\mathrm{p}$} & \multirow{2}{*}{$\begin{array}{l}\text { Irradiation energy, } \\
\mathrm{mJ} / \mathrm{cm}^{2}\end{array}$} \\
\hline & $\begin{array}{c}\text { Red light } \\
\text { (wavelength } 635 \mathrm{~nm} \text { ) }\end{array}$ & $\begin{array}{c}\text { Blue light } \\
\text { (wavelength } 405 \mathrm{~nm} \text { ) }\end{array}$ & $\begin{array}{c}\text { Green light } \\
\text { (wavelength } 532 \mathrm{~nm} \text { ) }\end{array}$ & \\
\hline 1 (control) & 0 & 0 & 0 & 0 \\
\hline 2 & 10 & 0 & 0 & 51.1 \\
\hline 3 & 0 & 10 & 0 & 51.1 \\
\hline 4 & 0 & 0 & 10 & 51.1 \\
\hline
\end{tabular}

The level of biomass accumulation was determined by the weight method, drying the mycelium to a constant mass at a temperature of $(105 \pm 1){ }^{\circ} \mathrm{C}[12]$.

To quantify the endopolysaccharides, a crushed $100 \mathrm{mg}$ portion of dry mycelium was taken, transferred to a $20 \mathrm{ml}$ tube, $5 \mathrm{ml}$ of $1 \mathrm{M} \mathrm{NaOH}$ was added, capped and extracted in a thermostat at $60{ }^{\circ} \mathrm{C}$ for $1 \mathrm{~h}$, stirring occasionally. The resulting extract was centrifuged for $20 \mathrm{~min}$ at $6000 \mathrm{rpm}$. The precipitate was separated, the content of endopolysaccharides in the supernatant was determined by phenol-sulfur method [13].

To determine the concentration of exopolysaccharides first carried out the precipitation of $5 \mathrm{ml}$ of culture fluid $10 \mathrm{ml}$ of $96 \%$ ethanol and settling during the day at $(4 \pm 1){ }^{\circ} \mathrm{C}$, after which the precipitate was separated by centrifugation for 25 minutes at $6000 \mathrm{rpm}$, dissolved in $5 \mathrm{ml}$ of hot distilled water and took $2 \mathrm{ml}$ of a solution in which the amount of exopolysaccharides was determined by the phenol-sulfur method [13].

All experiments were performed in triplicate. To determine the probability of the effect of laser radiation on the amount of biomass and polysaccharides used the method of analysis of variance. Comparison of mean values was performed by the Dunnett method [14]. Processing was performed using a package of statistical programs created at the Department of Plant Physiology and Biochemistry of DonNU named after Vasyl Stus [15].

\section{Research results and their discussion}

Analysis of the results of our studies shows a positive effect of radiation on the accumulation of biomass by the studied strains of the fungus $P$. ostreatus. In particular, for $P$. ostreatus, green light irradiation with a wavelength of $532 \mathrm{~nm}$ (irradiation energy $51.1 \mathrm{~mJ} / \mathrm{cm}^{2}$ ) was the most effective. Under the action of this irradiation regime, the best response to light was observed for strain P-192 - the amount of biomass increased by $71.4 \%$ according to the control. For strains R-191 and R155 biomass increased by $60 \%$ and $53.5 \%$, respectively. For strains P-108, P-154 and P-6v, the amount of biomass increased from 33.3 to $50 \%$, respectively. Laser irradiation with red light with a wavelength of $635 \mathrm{~nm}$ (irradiation energy $51.1 \mathrm{~mJ} / \mathrm{cm}^{2}$ ) led to an increase in biomass for all studied strains in the range from $16 \%$ to $25 \%$, and for strain P-155 this figure increased by $35.7 \%$. Irradiation of the mycelium with blue light with a wavelength of $405 \mathrm{~nm}$ (irradiation energy $51.1 \mathrm{~mJ} / \mathrm{cm}^{2}$ ) caused an increase in mycelial biomass for all studied strains of $P$. ostreatus in the range from 11.9 to $31.2 \%$, respectively (Fig. 2).

We first established the content of endopolysaccharides in the biomass of the fungus and exopolysaccharides in the culture fluid under the action of laser irradiation (Fig. 3). For strain P-192 P. ostreatus, the results were as follows: the most effective is green light irradiation with a wavelength of $532 \mathrm{~nm}$ (irradiation energy $51.1 \mathrm{~mJ} / \mathrm{cm}^{2}$ ). Under the action of this irradiation regime, the amount of mycelium endopolysaccharides increased by $42.0 \%$ according to the control. For strains P-191 and $\mathrm{P}-6 \mathrm{v}$, the amount of endopolysaccharides increased by $39.3 \%$ and $38.7 \%$, respectively. For strains P-108, $\mathrm{P}-155$ and $\mathrm{P}-154$, the amount of mycelium endopolysaccharides increased from $30.7 \%$ to 35.8 , respectively. We also detected a mycelial reaction in response to the action of blue light with a wavelength of $405 \mathrm{~nm}$ (irradiation energy $51.1 \mathrm{~mJ} / \mathrm{cm}^{2}$ ). In particular, under this mode of photostimulation, the amount of mycelium endopolysaccharides increased from $12.5 \%$ to $16.6 \%$ for all studied strains. R-108, R-155 and R-154 from $15.3 \%$ to $16.6 \%$ respectively. Slightly lower values for this mode of irradiation were found for strains P-191, P-192 and P-6v from 6.2 to $6.6 \%$, respectively (Fig. 3). 


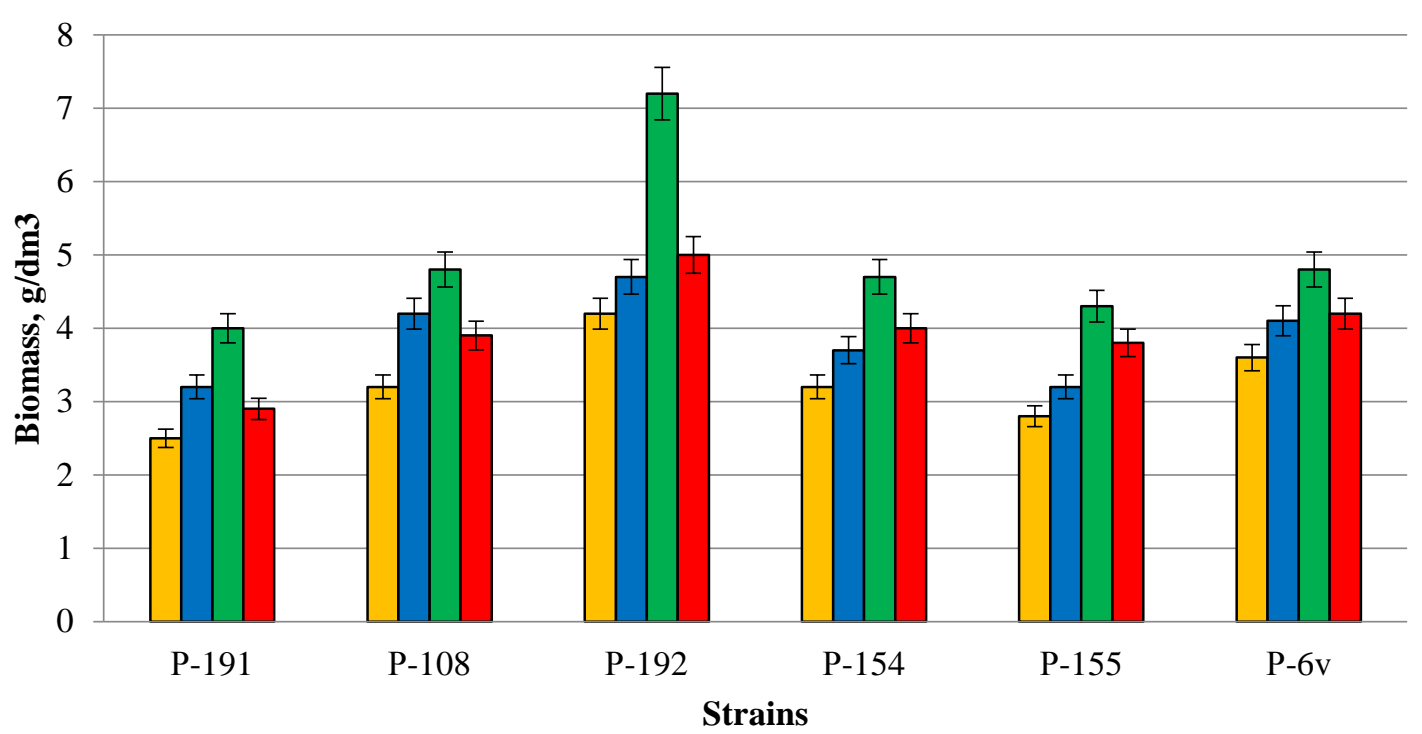

Fig. 2. The effect of laser irradiation on the amount of biomass of Pleurotus ostreatus strains when cultured on glucosepeptone medium. 12 days of cultivation: $\square$ - without irradiation; $\square-405 \mathrm{~nm} ; \square-635 \mathrm{~nm} ; \square-532 \mathrm{~nm}$

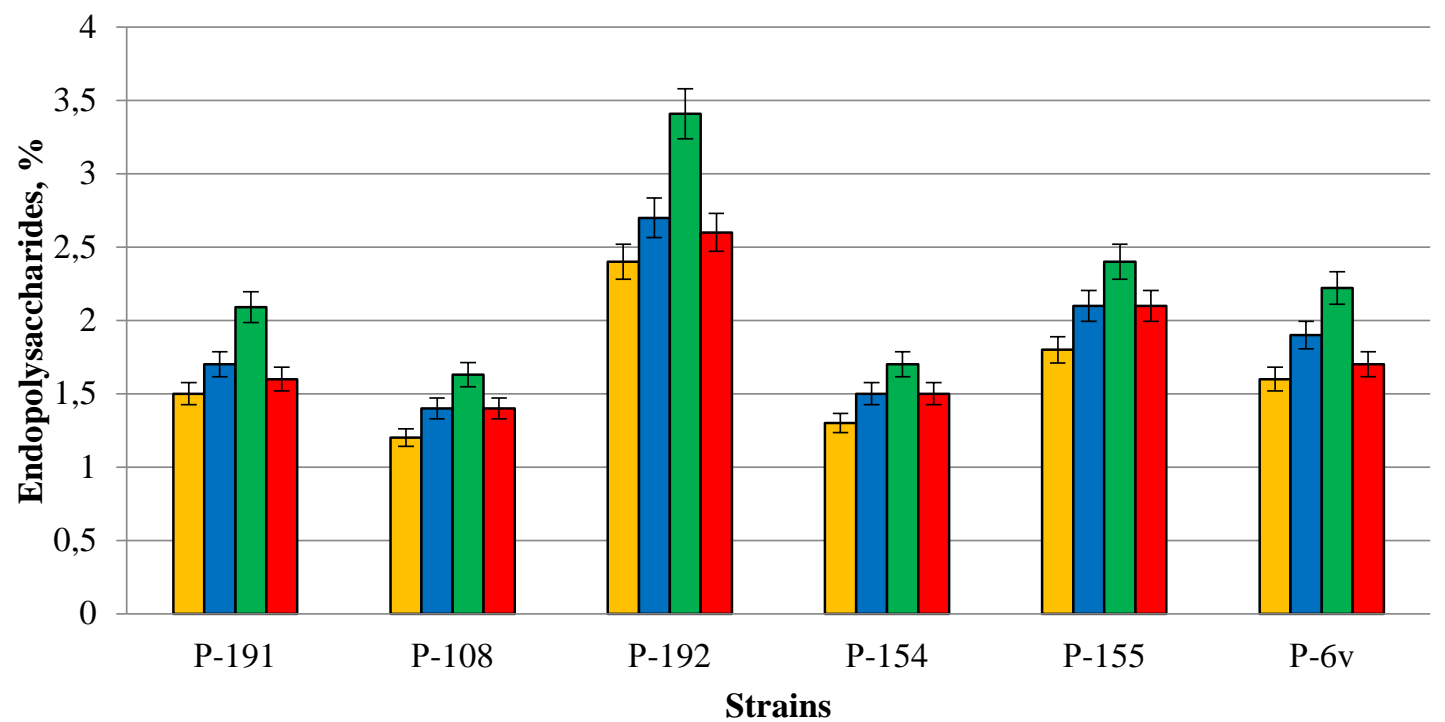

Fig. 3. The content of endopolysaccharides of Pleurotus ostreatus strains when cultured on glucose-peptone medium under the action of laser irradiation. 12 days of cultivation:

$\square$ - without irradiation; $\square_{-405 \mathrm{~nm}} \square_{-635 \mathrm{~nm}} \square_{-532 \mathrm{~nm}}$

Data on the amount of exopolysaccharides were slightly lower and varied depending on the irradiation regime. For strain P-192 P. ostreatus, the most effective was irradiation with green light with a wavelength of $532 \mathrm{~nm}$ (irradiation energy $51.1 \mathrm{~mJ} / \mathrm{cm}^{2}$ ). Under the action of this irradiation regime, the content of exopolysaccharides increased by $30.5 \%$ according to the control. For strains P-154 and P-191, the amount of exopolysaccharides increased by $28.1 \%$ and $27.8 \%$, respectively. For strains P-108, P-155 and P-6v the content of exopolysaccharides increased from $24.6 \%$ to $25.8 \%$, respectively. The amount of exopolysaccharides under the action of irradiation of mycelium with blue light at a wavelength of $405 \mathrm{~nm}$ (irradiation energy $51.1 \mathrm{~mJ} / \mathrm{cm}^{2}$ ) increased from $11.6 \%$ to $20.0 \%$ for all studied strains Laser irradiation of mycelium with red light at a wavelength of $635 \mathrm{~nm}$ (energy about $51.1 \mathrm{~mJ} / \mathrm{cm}^{2}$ ) caused an increase in the content of exopolysaccharides for all studied strains from $9.2 \%$ to $16.6 \%$, respectively (Fig. 4). 


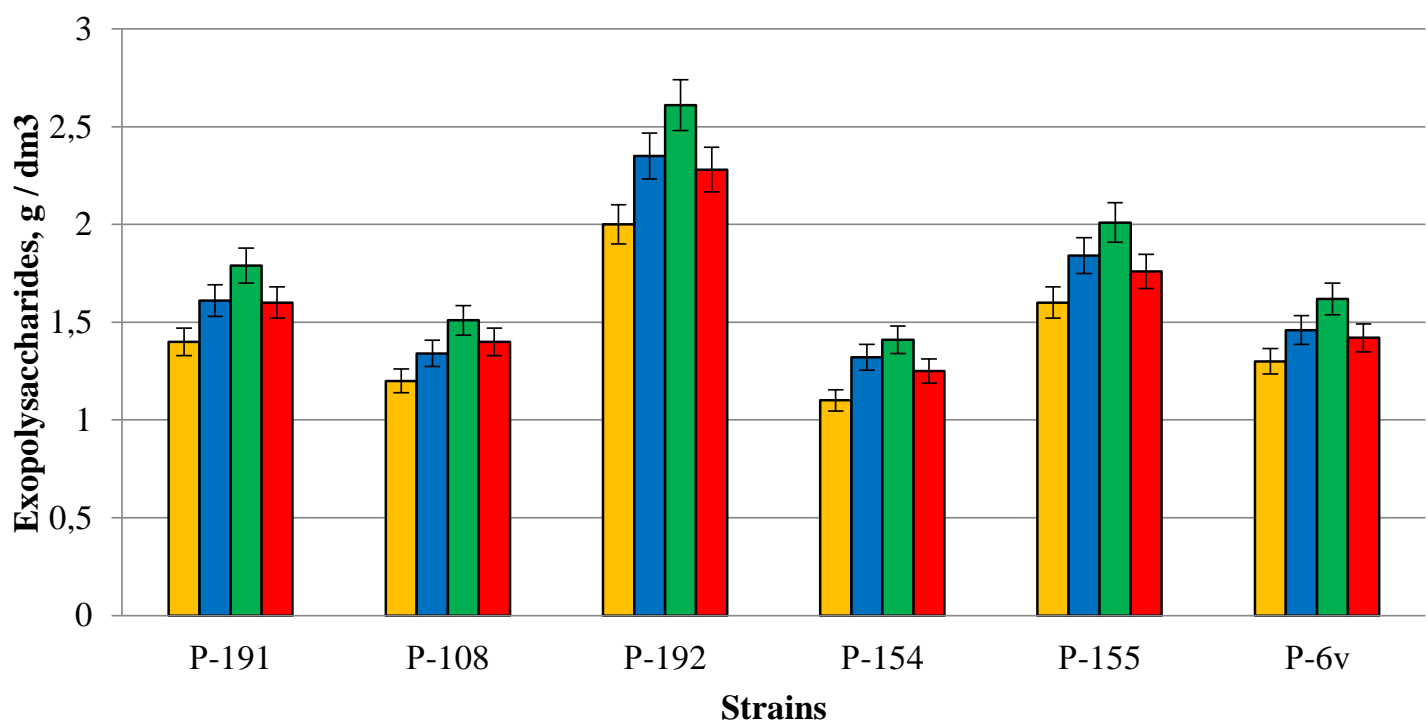

Fig. 4. The content of exopolysaccharides of Pleurotus ostreatus strains when cultured on glucose-peptone medium under the action of laser irradiation. 12 days of cultivation:

$\square$ - without irradiation; $\square-405 \mathrm{~nm} ; \square_{-635 \mathrm{~nm} ;} \square_{-532 \mathrm{~nm}}$

\section{Research results discussion}

It is known from the literature that the growth of biomass accumulation during cultivation varies depending on the strain and irradiation regime. In particular, for $F$. velutipes (coherent light with a wavelength of $488.0 \mathrm{~nm}$ ) biomass increased by $34.2 \%$, for P. ostreatus (coherent light with a wavelength of $632.8 \mathrm{~nm}$ ) by $41.8 \%$ [5]. Structural polysaccharides and chitin are important components of the cell wall of fungi. The presence of polysaccharides in the biomass of $P$. ostreatus during the cultivation of mycelium on different substrates has been established [9]. Our data on the content of polysaccharides of $P$. ostreatus correspond to the literature $[8,16]$, but are slightly lower. In our opinion, this may be due to the composition of nutrient media used by other scientists, in particular the presence of complex organic components, such as oat seed meal, milk thistle, flax, pumpkin, mustard, rose hips, wheat germ, amaranth seed meal, cake from rapeseed, sunflower seeds, red rice, walnut, yam, sweet and ordinary potato, cattail rhizome, plantain, etc.

We have for the first time obtained interesting data on the effect of laser irradiation on the synthesis of biomass and polysaccharides of the fungus $P$. ostreatus. According to which there is a significant increase in the amount of biomass and synthesis of polysaccharides under the action of irradiation of the mycelium with green light with a wavelength of $532 \mathrm{~nm}$ for $10 \mathrm{~s}$. The results obtained by us demonstrate the prospects of using laser irradiation for targeted regulation of biomass and polysaccharide synthesis.

Study limitations. It should be noted that this study was limited by the number of options used with a certain wavelength of light, as it requires re-equipment of the device. In addition, the data obtained reflect the reaction of strains only to specific light, which was used in our studies with a well-defined wavelength.

Prospects for further research. At the same time, we found differences in the photosensitivity of the studied strains of the $P$. ostreatus fungus depending on the wavelength of light makes it necessary to further search for more effective modes of photostimulation.

\section{Conclusions}

1. It was found that laser irradiation of mycelium with green $(532 \mathrm{~nm})$, blue $(405 \mathrm{~nm})$ and red $(635 \mathrm{~nm})$ light (irradiation energy $51.1 \mathrm{~mJ} / \mathrm{cm} 2$ ) leads to an increase in the amount of mycelial biomass of the studied strains of $P$. ostreatus.

2. It was investigated that laser irradiation with green (wavelength $532 \mathrm{~nm}$ ), blue (wavelength $405 \mathrm{~nm}$ ) and red light with a wavelength of $635 \mathrm{~nm}$ (irradiation energy $51.1 \mathrm{~mJ} / \mathrm{cm}^{2}$ ) contributes to the increase of endopolysaccharides in biomass and exopolysaccharides in the culture fluid of the studied strains of $P$. ostreatus.

3. The most effective mode of photoactivation of $P$. ostreatus mycelium for obtaining target products was determined. In particular, the best response was observed in response to green light at $532 \mathrm{~nm}$ for strain P192 - the amount of biomass increased by $71.4 \%$, the amount of mycelium endopolysaccharides increased by $42.0 \%$, and the content of exopolysaccharides increased by $30.5 \%$.

\section{Conflict of interest}

The authors declare that they have no conflicts of interest. 


\section{References}

1. Belova, N. V., Denisova, N. P. (2005). Griby beloi gnili i vozmozhnost ikh ispolzovaniia dlia utilizatsii otkhodov. Biotekhnologiia, 4, 55-58.

2. Dunaevskii, Ia. E., Dun Chzhan, Matveeva, A. R. et. al. (2006). Degradatsiia belkovykh substratov ksilotrofnymi bazidiomitsetami. Mikrobiologiia, 75 (1), 46-51.

3. Patel, Y., Naraian, R., Singh, V. K. (2012). Medicinal properties of (Oyster mushroom): a review. World Journal of Fungal and Plant Biology, 3 (1), 1-12.

4. Gern, R. M. M., Wisbeck, E., Rampinelli, J. R., Ninow, J. L., Furlan, S. A. (2008). Alternative medium for production of Pleurotus ostreatus biomass and potential antitumor polysaccharides. Bioresource Technology, 99 (1), $76-82$. doi: http://doi.org/10.1016/j.biortech.2006.11.059

5. Poedinok, N. L. (2015). Biotekhnologicheskie osnovy intensifikatsii kultivirovaniia sedobnykh i lekarstvennykh makromitsetov s pomoschiu sveta nizkoi intensivnosti. Kiev, 387.

6. Reshetnyk, K., Prysedsky, Y., Yuskov, D. (2020). The influence of laser irradiation on the development of vegetative mycelium Pleurotus ostreatus. Biologija, 65 (4), 243-250. doi: http://doi.org/10.6001/biologija.v65i4.4118

7. Mshandete, A. M., Mgonja, J. R. (2009). Submerged liquid fermentation of some Tanzanian Basidiomycetes for the production of mycelial biomass, exopolysaccharides and mycelium protein using wastes peels media. ARPN Journal of Agricultural and Biological Science, 4 (6), 1-13.

8. Adebayo-Tayo, B. C., Jonathan, S. G., Egbomuche, R. C. (2011). Optimization of growth conditions for mycelial yield and exopolysaccharides production by Pleurotus ostreatus cultivated in Nigeria. African Journal of Microbiology Research, 5 (15), 2130-2138. doi: http://doi.org/10.5897/ajmr11.328

9. Petre, M., Petre, V.; Petre, M. (Ed.) (2013). Environmental biotechnology for bioconversion of agricultural and forestry wastes into nutritive biomass. Enviromental biotechnology-new approaches and prospective applications. Croatia: InTech, 1-22. doi: http://doi.org/10.5772/55204

10. Krupodorova, T. A., Barsteyn, V. Yu., Peshuk, L. V., Haschuk, O. I., Kostenko, E. E. (2014). Pleurotus ostreatus (Jacq.) Kumm. Cultivation on vegetable wastes. Biotechnologia Acta, 7 (4), 92-99. doi: http://doi.org/10.15407/biotech7.04.092

11. Poyedinok, N. L. (2013). Use of artificial light in mushroom cultivation. Biotechnologia Acta, 6 (6), 58-70. doi: http://doi.org/10.15407/biotech6.06.058

12. Dudka, I. A., Vasser, S. P., Ellanskaia, I. A. et. al. (1982). Metody eksperimentalnoi mikologii. Kyiv: Naukova dumka, 561. dumka, 238

13. Varbanets, L. D., Zdorovenko, G. M., Knirel, Iu. A. (2006). Metody issledovaniia endotoksinov. Kyiv: Naukova

14. Prysedskyi, Yu. H. (1999). Statystychna obrobka rezultativ biolohichnykh eksperymentiv. Donetsk: Kassyopeia, 210.

15. Prysedskyi, Yu. H. (2005). Paket prohram dlia provedennia statystychnoi obrobky rezultativ biolohichnykh eksperymentiv. Donetsk: DonNU, 84.

16. Scherba, V. V., Babitskaya, V. G., Truchonovec, V. V., Fomina, V. I., Bisko, N. A., Mitropolskaya, N. Y. (1999). The Influence of the Cultivation Conditions on the Chemical Composition of Medicinal Mushrooms Pleurotus ostreatus (Jacq.: Fr.) Kumm. and Lentinus edodes (Berk.) Sing. International Journal of Medicinal Mushrooms, 1 (2), 181-185. doi: http://doi.org/10.1615/intjmedmushrooms.v1.i2.80

Received date 11.05.2020

Accepted date 17.06.2020

Published date 30.06.2020

Kateryna Reshetnyk, Senior Lecturer, Department of Botany and ecology, Vasyl' Stus Donetsk National University, 600-richchia str., 21, Vinnitsa, Ukraine, 21021,

E-mail: k.reshetnyk@donnu.edu.ua 